\title{
Case Report of the Coincidence of Dubin and Johnson Syndrome and Colon Cancer
}

\author{
Ahmed H. Hamid, MBBS, MRCP ${ }^{1 *}$, J.M.Yousuf ${ }^{2}$, M. T. Yacoubi , MD, FEBP ${ }^{3}$
}

${ }^{1}$ Internist, National Guard Health Affair- Dammam

${ }^{2}$ Consultant Gastroenterology National Guard Hospital, Dammam

${ }^{3}$ Consultant Anatomic Pathology, National Guard Hospital Al Hasa

DOI: $10.36347 /$ simcr.2020.v08i04.021

| Received: 20.03.2020 | Accepted: 30.03.2020 | Published: 30.04 .2020

*Corresponding author: Ahmed H. Hamid

Abstract

Introduction: Dubin and Johnson syndrome (DJS) is autosomal recessive, inherited disorder with no progression to end-stage Liver disease.it result in mainly unconjugated hyper bilirubinaemia. Clinical onset of DJS often begin during the teenage years or in early adulthood. There are case reports describe the coincidence of DJS and colon cancer. Brief case report: We describe 27 years old male diagnosed with adenocarcinoma of the colon few years after the clinical onset of DJS. Conclusion: Attention should be taken when evaluating a young adult with DJS and be aware of this risk and consequences of a late diagnosis of colorectal cancer.

Keywords: Dubin-Johnson syndrome, Hyperbilirubinemia Colon Cancer.

Copyright @ 2020: This is an open-access article distributed under the terms of the Creative Commons Attribution license which permits unrestricted use, distribution, and reproduction in any medium for non-commercial use (NonCommercial, or CC-BY-NC) provided the original author and source are credited.

\section{INTRODUCTION}

IN 1954, Dubin and Johnson' reported 12 cases of chronic jaundice characterized by elevation of both direct and indirect serum bilirubin, autosomal recessive, inherited disorder with no progression to end-stage Liver disease. Both the conjugated and unconjugated form of bilirubin can be elevated in DJS subjects, with the former ranging from $17 \%$ to $88 \%$ of the total bilirubin with a mean value of $60 \%[1,2]$, in addition to the fluctuating jaundice. DJS subjects may suffer from nonspecific symptoms such as weakness and abdominal discomfort. Urinary coproporphyrin output is normal [11]. Thus, the biliary excretion of anionic dyes including bromosulfophthalein, indocyanine green and cholescintigraphy radiotracers is delayed. Liver histology in DJS shows an accumulation of distinctive melanin-like lysosomal pigment in an otherwise normal liver, which gives the organ a characteristic dark pink or even black colour [1-3]. Clinical onset of DJS is often seen during the teenage years or in early adulthood, which is typical to our patient. In this report, we describe 27 years old male diagnosed with adenocarcinoma of the colon few years after the clinical onset of DJS. However, the relationship between DJS and colon cancer not yet fully understood.

\section{Case Report}

This 29 years old male, first time seen in the gastroenterology clinic in June 2013 when he presented by intermittent right hypochondrial pain and jaundice for almost three months. There was no itching, or weight loss. For instance, he has no evidence of gastrointestinal bleeding or Porto systemic encephalopathy. He did not consume alcohol or smoke. He has no family history of jaundice. At this stage his liver profile show: (GTP 91- Bili D 73.1 - Bili T 101.5 Alk Phos 95- TP 76- Alb 46 - ALT 41- AST 23).

Screen for hepatic autoimmune and viral serology requested and result came back as following: (Hepatitis C Antibody, HBsAg, HBE AG, CMV IgM, ANA-H) ALL negative, AntiHbs $>1000.00$. Transferrin 2.57 Ceruloplasmin $(0,23)$. Liver/Kidney Mic antibody (1.25), anti-smooth muscle antibody less than (1:20).

The work up point toward isolated unconjugated hyperbilirubinemia. Therefore, MRCP requested on June 2013 Findings were highly suggestive of early primary sclerosing cholangitis. Other possibility like eosinophilic cholangitis and HIV related cholangiopathy to be consider. Correlation with ERCP or liver biopsy was recommended. 
With this finding the patient referred to the gastroenterology center at King Abdul-Aziz Medical City in Riyadh for liver biopsy and possible ERCP.

Patient was seen there and started on ursodeoxycholic acid 300 bid with the differential diagnosis of sclerosing cholangitis versus DubinJohnson syndrome. In addition, to repeat MRCP after two years. However, later on March -2015 they decide to do a liver biopsy, which confirm the diagnosis of Dubin-Johnson syndrome.

Patient remain asymptomatic till November 2017 when he has been referred again to our clinic from the general practitioner with complain off right upper quadrant pain on and off associated with intermittent bleeding per rectum, occasional constipation and weight loss. During an examination, he was vitally stable, his abdomen was soft and lax no organomegaly or enlarged lymph nodes detected .Patient booked for upper and lower endoscopy

\section{UPPER ENDOSCOPY}

Esophagus Normal, Stomach Normal, Duodenum Normal.

\section{Colonoscopy}

Scope passed up to Terminal ileum, a large polypoid tumor seen in rectum, $7-10 \mathrm{~cm}$ from anal verge looks malignant.

\section{Then we requested CT scan chest / abdomen and pelvic which show:}

Eccentric polypoidal rectal thickening is seen involving the right lateral wall of the rectum with somewhat angulated margins, stranding of fat and thickening of the right mesorectal fascia and a questionable small lymph node in the right internal iliac chain. Further evaluation by MRI pelvis will be of help for better characterization of the lesion. No evidence of chest or abdominal metastasis is seen. No osseous metastasis is identified.

\section{MRI Pelvis Show}

IMPRESSION: A low- mid rectal flat polypoidal soft tissue mass lesion is likely representing rectal cancer with suspicion of extramural venous invasion. No internal sphincter involvement is seen. No regional lymph node is seen.

Rectum, Proctocolonoscopic biopsy show: moderately differentiated adenocarcinoma (low grade).

We break the bad news to our patient and he had referred to a near oncology center for further treatment.

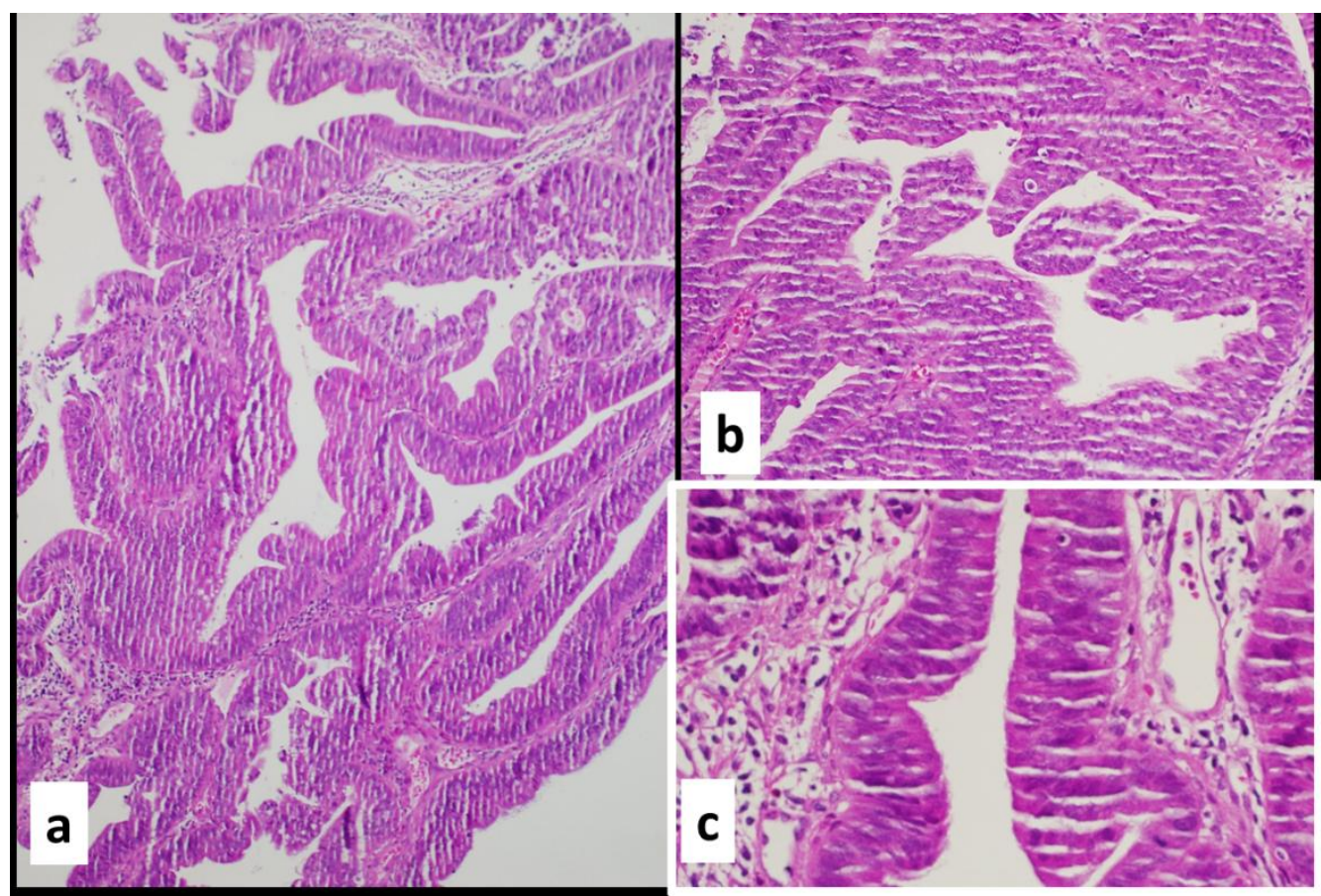

Figure- a: HE staining x 100, b: HE staining x 200, c: HE staining x 400: malignant, cribriform and glandular proliferation with atypia, apoptotic cells and abnormal mitoses 


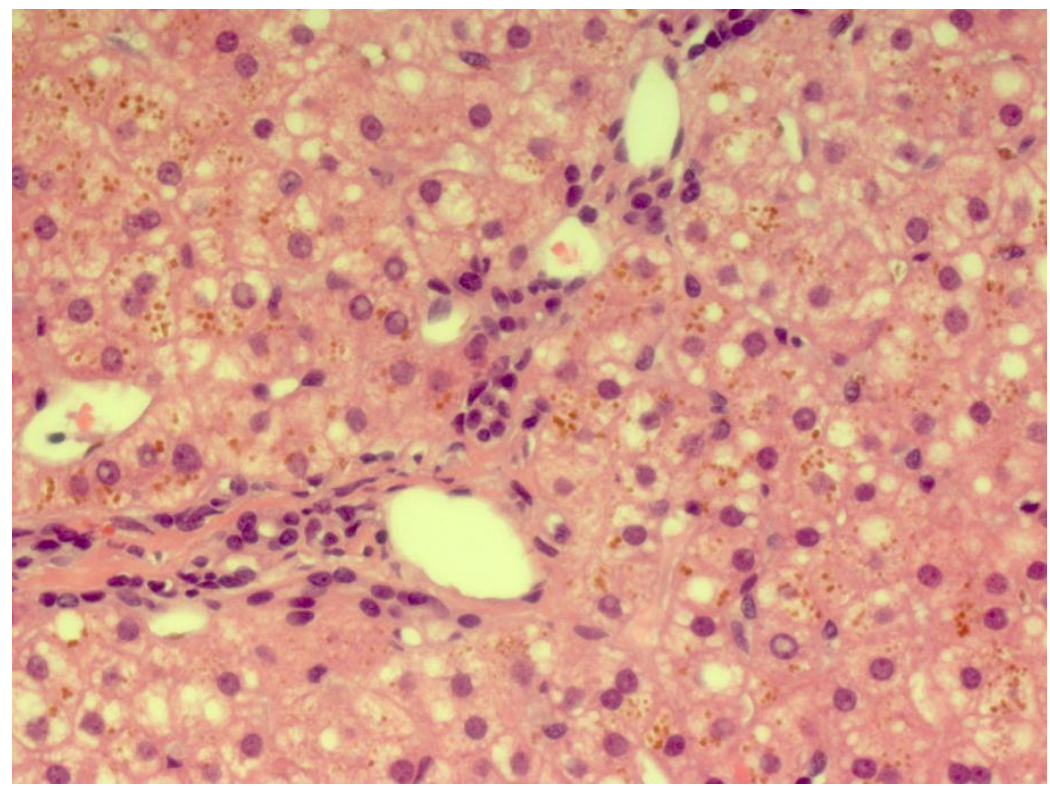

Figure-B: the liver biopsy

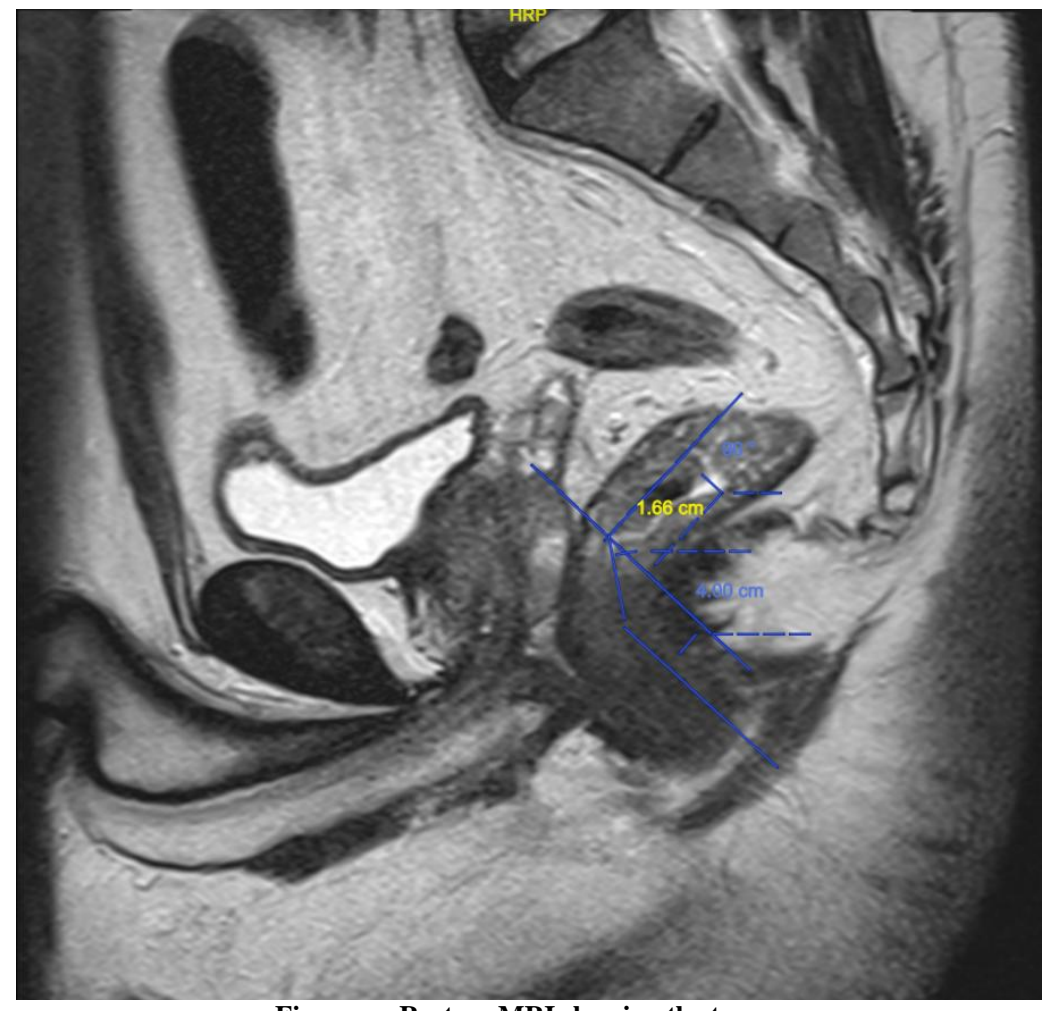

Figure- c: Rectum MRI showing the tumor

\section{Discussion}

The molecular basis in Dubin-Johnson syndrome is absence or deficiency of human canalicular multispecific organic anion transporter MRP2/cMOAT caused by homozygous or compound heterozygous mutation(s) in ABCC2 located on chromosome 10q24 [10] this result in mainly in unconjugated hyper bilirubinaemia. There are reports describing the protective effect of bilirubin on the development of cancer emphasizing the antioxidative and antiinflammatory effect of bilirubin [8]. In exploratory case-control study was based on 777 CRC patients and
986 controls from the Czech Republic, lower serum bilirubin levels were detected in CRC patients compared to the controls $(\mathrm{p}<0.001)$; each $1 \mu \mathrm{mol} / \mathrm{L}$ decrease in serum bilirubin was associated with a $7 \%$ increase of CRC risk ( $<$ 0.001) [6]. The fact that our patient with DJS developed colorectal adenocarcinoma few years after he diagnosed with DJS, This indicates that hyperbilirubinemia may not be sufficient to protect cancer development. Even more, there are case reports describe the coincidence of DJS and colon cancer [7]. Adenocarcinoma of the colon is the most common histopathological type of colorectal carcinoma. It ranks 
fourth in men and third in women in Western Europe and the US and overall accounts for $98 \%$ of cancers of the large intestine [5]. Screening is recommended in many countries. In a recent study once only flexible sigmoidoscopy screening or flexible sigmoidoscopy and FOBT reduced colorectal cancer incidence and mortality on a population level compared with no screening. Screening was effective both in the 50- to 54-year and the 55- to 64-year age groups, absolute rate difference, 28.4 [95\% CI, 12.1-44.7]; HR, 0.80 [95\% CI, 0.70-0.92]) [4]. As it is widely considered a disease that affects people after the 5 th decade of life, screening is not indicated before 50 years of age [9]. Until we find the answers to some of these doubts, doctors must put attention when evaluating a young adult with DJS and be aware of this risk and consequences of a late diagnosis of colorectal cancer.

\section{Conclusion}

In view of the all of the above, we think the link between DJS and colon cancer should be consider in future researches, to stablish large epidemiological study will lead to understand more about the coincidence of DJS and colon cancer. Finding screening criteria in-patient with DJS for colon cancer can help in early diagnosis and of course good outcome of the treatment.

\section{Consent}

Written informed consent was obtained from the patient for publication of this case report.

\section{REFERENCES}

1. Dubin IN, Johnson FB. Chronic idiopathic jaundice with unidentified pigment in liver cells; a new clinicopathologic entity with a report of 12 cases. Medicine (Baltimore) 1954.

2. Shani M, Seligsohn U, Gilon E, Sheba C, Adam A. Dubin-johnson syndrome in israel: I. Clinical, laboratory, and genetic aspects of 101 cases1. QJM: An International Journal of Medicine. 1970 Oct 1;39(4):549-67.

3. Sprinz H, Nelson RS. Persistent non-hemolytic hyperbilirubinemia associated with lipochrome- like pigment in liver cells: report of four cases. Ann Intern Med, 1954;41: 952-962.

4. Holme $\varnothing$, Løberg M, Kalager M, Bretthauer M, Hernán MA, Aas E, Eide TJ, Skovlund E, Schneede J, Tveit KM, Hoff G. Effect of flexible sigmoidoscopy screening on colorectal cancer incidence and mortality: a randomized clinical trial. Jama. 2014 Aug 13;312(6):606-15.

5. Tumwine LK, Kagimu M, Ocama P, Segamwenge I, Masiira-Mukasa N, Wamala D, Dworak O, Opio CK. Atypical presentation of colon adenocarcinoma: a case report. Journal of medical case reports. 2012 Dec 1;6(1):58

6. Jirásková A, Novotný J, Novotný L, Vodička P, Pardini B, Naccarati A, Schwertner HA, Hubáček JA, Punčochářová L, Šmerhovský Z, Vítek L. Association of serum bilirubin and promoter variations in HMOX1 and UGT1A1 genes with sporadic colorectal cancer. International journal of cancer. 2012 Oct 1;131(7):1549-55.

7. Sticova E, Elleder M, Hulkova H, Luksan O, Sauer M, Wunschova-Moudra I, Novotny J, Jirsa M. Dubin-Johnson syndrome coinciding with colon cancer and atherosclerosis. World Journal of Gastroenterology: WJG. 2013 Feb 14;19(6):946950.

8. Stocker R, Yamamoto Y, McDonagh AF, Glazer AN, Ames BN. Bilirubin is an antioxidant of possible physiological importance. Science. 1987;235:1043-1046.

9. Deen KI, Silva H, Deen R, Chandrasinghe PC. Colorectal cancer in the young, many questions, few answers. World journal of gastrointestinal oncology. 2016 Jun 15;8(6):481-88.

10. Paulusma CC, Kool M, Bosma PJ, Scheffer GL, ter Borg F, Scheper RJ, Tytgat GN, Borst P, Baas $\mathrm{F}$, Oude Elferink RP. A mutation in the human canalicular multispecific organic anion transporter gene causes the Dubin-Johnson syndrome. Hepatology, 1997; 25:1539-1542.

11. Haimi-Cohen Y, Merlob P, Marcus-Eidlits T, Amir J. Dubin-Johnson syndrome as a cause of neonatal jaundice: the importance of coproporphyrins investigation. Clinical pediatrics. 1998 Aug;37(8):511-3. 